\title{
Cough associated with captopril and enalapril
}

\author{
D M COULTER, I R EDWARDS
}

\begin{abstract}
Thirty three reports of cough associated with captopril and 26 associated with enalapril received by the New Zealand intensive medicines monitoring programme were reviewed. The programme is a specialised part of the New Zealand postmarketing surveillance system. Review of these reports showed that the cough was an adverse reaction to the drugs, occurred even with low dose treatment, and was severe enough to warrant withdrawal of the drugs in most of the cases reported. A significant sex difference was shown, with women predominating. The reaction seemed to be a greater problem with enalapril, and in seven patients it occurred with both captopril and enalapril. Withdrawal of treatment resulted in rapid recovery, and no long term effects were shown.

The pathogenesis of the reaction is unknown, but possible mediators include bradykinin and prostaglandins.
\end{abstract}

\section{Introduction}

A persistent dry cough has been observed in several studies with both captopril and enalapril, and in some cases the drug had to be withdrawn, with subsequent resolution of symptoms..$^{1-9}$ DiBianco, however, reported claims by the Federal Drug Administration that accumulated data from controlled studies did not show cough occurring with increased frequency, ${ }^{10}$ and another recent review concluded that the cough was probably unrelated to treatment. ${ }^{11}$

In this paper 33 reports of cough with captopril and 26 with enalapril from 52 patients are reviewed. These reports were received by the New Zealand Medicines Adverse Reactions Centre, and all had a strong relation with an angiotensin converting enzyme inhibitor.

\section{Patients and methods}

Captopril and enalapril have been included in the intensive monitoring programme since approval for marketing in New Zealand was given in April 1981 for captopril and in May 1984 for enalapril. The intensive monitoring programme aims to provide intensive postmarketing surveillance of selected new medicines for the first few years of marketing. ${ }^{12-14}$ This specialised aspect of postmarketing surveillance uses two primary sources of information. Firstly, doctors are asked to report spontaneously all adverse events-that is, all new clinical incidents as well as recognised or suspect reactions; sometimes this information is supplemented by survey. Secondly, dispensing pharmacists throughout the country are asked to record and send in prescription data for monitored medicines including the patient's name, address, date of birth, date of prescription, dose, and prescribing doctor. This is computerised, and a cohort of patients with prescription records for each of these medicines is thus established. These cohorts are estimated to contain about $80 \%$ of the total number of patients but cannot be used to calculate incidences because precise numbers of patients are unknown. Recently the use of duplicate prescription pads for the programme has been on trial in one region. The data received from this system are virtually

National Toxicology Group, University of Otago Medical School, PO Box 913, Dunedin, New Zealand

D M COULTER, $M B, C H B$, general practitioner and assistant to the medical assessor

I R EDWARDS, FRCP, FRACP, medical assessor, New Zealand Medicines Adverse Reactions Committee

Correspondence to: Dr Coulter. complete in items of numbers of patients and were therefore used as the denominator for the calculations of incidence.

Statistical comparisons of sex, age, and dose were made between the patients with cough and the cohorts. Variations in cohort totals were caused by missing data, which are presumed to have occurred in a random manner. The much smaller cohort numbers in table I result from relatively low compliance in entering date of birth on prescriptions. The cohort control data used were those covering the same time span as the reports of cough. Indications for use were compared with those given for other reports of adverse reactions because this information was not available from the cohort data.

\section{Results}

For both captopril and enalapril the mean age, median, and range of ages of patients with cough were similar to those of the patients in the respective cohorts (table I). Table II shows that there was a significantly greater proportion of women among the patients with cough compared with the patient cohorts. The age distributions of men and women within each group were similar (table III). No patient with cough taking captopril was under 50. Of the seven patients taking enalapril who had a cough and were under 50 , five were women.

TABLE I-Comparison of age (years) in patients with cough and cohorts

\begin{tabular}{lccccc}
\hline & \multicolumn{2}{c}{ Captopril } & & \multicolumn{2}{c}{ Enalapril } \\
\cline { 2 - 3 } \cline { 5 - 6 } \cline { 5 - 6 } & $\begin{array}{c}\text { Patients with cough } \\
(\mathrm{n}=33)\end{array}$ & $\begin{array}{c}\text { Cohort } \\
(\mathrm{n}=1933)\end{array}$ & $\begin{array}{c}\text { Patients with cough } \\
(\mathrm{n}=26)\end{array}$ & $\begin{array}{c}\text { Cohort } \\
(\mathrm{n}=494)\end{array}$ \\
\hline Mean age & $64 \cdot 8$ & $61 \cdot 1$ & & $57 \cdot 5$ & $57 \cdot 3$ \\
Median age & 64 & 62 & & 59 & 58 \\
Range & $51-84$ & $9-96$ & & $33-84$ & $12-94$ \\
\hline
\end{tabular}

TABLE II-Comparison of sex distribution in patients with cough and cohorts. Figures are numbers (percentages)

\begin{tabular}{lrrrrrr}
\hline & \multicolumn{2}{c}{ Patients with cough } & & \multicolumn{2}{c}{ Cohort } & \\
\cline { 2 - 3 } & \multicolumn{1}{c}{ Men } & Women & & Men & Women & Significance* \\
\hline Captopril & $10(30 \cdot 3)$ & $23(69 \cdot 7)$ & & $2563(54 \cdot 7)$ & $2121(45 \cdot 3)$ & $\mathrm{p}=0.005$ \\
Enalapril & $9(34 \cdot 6)$ & $17(65 \cdot 4)$ & & $546(57 \cdot 0)$ & $411(43 \cdot 0)$ & $\mathrm{p}=0.023$ \\
\hline
\end{tabular}

${ }^{\star} \chi^{2}$ test.

TABLE III-Distribution of age (years) by sex in patients with cough

\begin{tabular}{lcclcc}
\hline & \multicolumn{2}{c}{ Captopril } & & \multicolumn{2}{c}{ Enalapril } \\
\cline { 2 - 3 } \cline { 5 - 6 } & $\begin{array}{c}\text { Men } \\
(n=10)\end{array}$ & $\begin{array}{c}\text { Women } \\
(n=23)\end{array}$ & & $\begin{array}{c}\text { Men } \\
(n=9)\end{array}$ & $\begin{array}{c}\text { Women } \\
(n=17)\end{array}$ \\
\hline Age range & $51-84$ & $53-71$ & & $33-75$ & $39-84$ \\
Mean age & $65 \cdot 0$ & $64 \cdot 7$ & & $55 \cdot 9$ & $58 \cdot 3$ \\
Median age & 65 & 64 & & 55 & 59 \\
\hline
\end{tabular}

Table IV shows the indications for use of captopril and enalapril among the patients with cough and among patients with other adverse reactions. Most patients with cough were being treated for hypertension; the mean dose used for treating hypertension was twice that used for treating heart failure. The proportion of patients being treated for hypertension in the groups with cough, however, did not differ significantly from that in the groups with other adverse reactions. The mean doses for captopril were 
higher in the patients with other reactions than in the patients with cough; the mean doses of enalapril were similar in the two groups.

Table V compares doses in the groups with cough with those in the cohorts regardless of indication. The means for enalapril were similar, but the mean for captopril was higher in the cohort $(t$ test, $p<0.001)$. Only two patients with cough who were taking captopril received doses greater than $100 \mathrm{mg}$ daily, and seven received less than $25 \mathrm{mg}$. Two of the patients taking enalapril received only $5 \mathrm{mg}$ daily, and both of these patients and six of the seven taking a low dose of captopril had to be withdrawn from treatment. Overall, symptoms were sufficiently severe to warrant withdrawal in 25 (76\%) patients taking captopril and $23(88 \%)$ taking enalapril. This difference was not significant $\left(\chi^{2}\right.$ test, $\left.\mathrm{p}=0 \cdot 21\right)$.

TABLE IV-Comparison of indications for use

\begin{tabular}{|c|c|c|c|c|}
\hline & \multicolumn{2}{|c|}{ No (\%) of patients } & \multicolumn{2}{|c|}{ Mean dose (mg/day) } \\
\hline & Patients with cough & Cohort & Patients with cough & Cohor \\
\hline \multicolumn{5}{|l|}{ Captopril: } \\
\hline Hypertension & $23(69 \cdot 7)$ & $164(64 \cdot 1)$ & $56 \cdot 0$ & $70 \cdot 3$ \\
\hline Heart failure & $10(30 \cdot 3)$ & $92(35.9)$ & $25 \cdot 0$ & $46 \cdot 8$ \\
\hline \multicolumn{5}{|l|}{ Enalapril: } \\
\hline Hypertension & $23(88 \cdot 5)$ & $73(83 \cdot 0)$ & $16 \cdot 7$ & $15 \cdot 3$ \\
\hline Heart failure & $3(11 \cdot 5)$ & $15(17 \cdot 0)$ & $8 \cdot 3$ & $10 \cdot 3$ \\
\hline
\end{tabular}

TABLE V-Comparison of dosages in patients with cough and cohorts

\begin{tabular}{lccccc}
\hline & \multicolumn{2}{c}{ Captopril } & & & \multicolumn{2}{c}{ Enalapril } \\
\cline { 2 - 3 } \cline { 5 - 6 } \cline { 5 - 6 } & $\begin{array}{c}\text { Patients with cough } \\
(\mathrm{n}=32)\end{array}$ & $\begin{array}{c}\text { Cohort } \\
(n=4710)\end{array}$ & $\begin{array}{c}\text { Patients with cough } \\
(\mathrm{n}=26)\end{array}$ & $\begin{array}{c}\text { Cohort } \\
(\mathrm{n}=969)\end{array}$ \\
\hline Mean dose (mg/day) & $48 \cdot 1$ & $66 \cdot 4$ & & $15 \cdot 8$ & $16 \cdot 8$ \\
Median dose (mg/day) & $43 \cdot 8$ & $50 \cdot 0$ & & $15 \cdot 0$ & $10 \cdot 0$ \\
Range & $6 \cdot 25-200$ & $6 \cdot 25-450$ & & $5-40$ & $2 \cdot 5-80$ \\
\hline
\end{tabular}

Information on the time taken for the cough to develop was available for 10 patients taking captopril and nine taking enalapril; the mean was nine weeks for captopril and $4 \cdot 1$ weeks for enalapril. This difference was not significant ( $t$ test using $\log$ (time), $0.5<\mathrm{p}<0.6$ ).

Typical symptoms were a persistent, paroxysmal, dry cough that was sometimes severe enough to disturb sleep or cause vomiting and was at times debilitating. Three patients had had a pre-existing cough, but this had become distinctly worse; it returned to the previous level on withdrawal of the drug. In all the other patients withdrawal of the drug resulted in clearance of the cough. The recovery time was available for seven patients taking captopril and six taking enalapril; mean recovery time was 3.4 days (range 1-7) for captopril and $5 \cdot 5$ days (1-14) for enalapril. This difference was significant ( $t$ test using $\log$ (time), $0.01<\mathrm{p}<0.02$ ).

Nine patients were rechallenged after recovery, five with enalapril and four with captopril; the cough recurred in all nine. Seven patients (six of whom were women) developed a cough when exposed to captopril and enalapril in turn. Four had started treatment with enalapril. One in each group had less cough with the second medicine and was able to continue treatment.

Four patients had a history of asthma, but only one had increased wheeze (with enalapril). Two other patients, one each taking captopril and enalapril, complained of wheeze associated with their cough; one of these patients was also taking atenolol. There were seven other adverse events in four patients who had a cough: one had fever, night sweats, rash, and dry mouth, and the three others had dysgeusia, urticaria, and recurrent sore throats.

Eighteen of the total of 52 patients did not take any other drugs. The 34 other patients took a total of 34 different drugs. Of these, diuretics (23 patients), $\beta$ blockers (10), digoxin (eight), and calcium channel blockers (seven) were those used most commonly. Five patients were reported as having investigations that included chest radiography, respiratory function tests, and, in one patient, a gastroscopy. In one patient an otolaryngologist described a "velvety pachyderma between the arytenoids." This was the only abnormal finding and probably resulted from irritation by the cough.

The actual incidence of cough could not be calculated because of possible failure to report this unexpected association with angiotensin converting enzyme inhibitors. An accurate incidence of reported cough reactions, however, was derived from data from the trial of duplicate prescriptions. These data came from one region consisting of $8 \%$ of the total population of
New Zealand. For captopril there were 13 spontaneous reports from 1214 patients $(1 \cdot 1 \%)$, and for enalapril seven reports from 250 patients $(2 \cdot 8 \%)$. This incidence of cough was significantly greater for enalapril $\left(\chi^{2}\right.$ test, $\mathrm{p}=0.032$ )

The longest time for which a patient had a cough was 15 months (treatment was with captopril); recovery occurred two days after withdrawal of the drug. The longest time for which a patient taking enalapril had a cough was 21 weeks, with recovery in five days. There was no significant difference in recovery time between patients with a cough of four months' duration or longer (four taking captopril and four taking enalapril) and other patients.

\section{Discussion}

There has been some hesitation in recognising cough as a reaction to enalapril and captopril, ${ }^{15}$ and its incidence has been considered no greater than that found in a group taking placebo or controls and probably of no importance..$^{381016}$ Only occasionally has it been described as a "possible" adverse effect. ${ }^{25}$ Several reviews have not mentioned cough. ${ }^{17-26}$ One report regarded it as rare, ${ }^{9}$ and, although several authors have described the cough as a reaction, ${ }^{1+6727}$ there has evidently been a delay in recognising that cough can be a frequent and distressing reaction to both captopril and enalapril. The reports received by the Medicines Adverse Reactions Committee show that this cough is a clear cut adverse reaction that is an important cause of withdrawal from treatment and recurs on rechallenge.

The cough seemed to be sex related, with women more likely to develop it; this difference was significant for both captopril and enalapril. This observation may help in the elucidation of the pathogenesis of the cough; interestingly, there are 10 women in the 12 published case reports. ${ }^{146-8}$

The cough reaction was common with low dose treatment and did not seem to be dose related. The mean doses of enalapril in the group with cough and the cohort were similar; the mean dose of captopril was actually higher in the cohort, which probably reflected earlier recommendations for higher dosages. A similar pattern was seen when mean doses were compared with those in the patients with other adverse reactions (table IV). Cough might be expected to be more common with heart failure than hypertension, but when the data were compared with data from the group with other adverse reactions such a trend was not seen.

After treatment was stopped recovery from the cough seemed to be rapid and complete and there was no indication of long term effects. There was also no evidence that the cough was part of a syndrome or an interaction as there was no regular association with other adverse events or other medicines. Two patients complained of wheeze with their cough, but there seemed to be no definite association of the cough reaction with asthma, although exacerbation of asthma has been reported ${ }^{6}$ and occurred in one of the four patients with asthma in this series. Challenge with methacholine does not produce wheeze in patients with the cough reaction. ${ }^{28}$

Though the incidence of reported cases of cough was $1 \cdot 1 \%$ for captopril and $2 \cdot 8 \%$ for enalapril, based on one region of New Zealand, these were all spontaneous reports and the number of unreported cases was unknown, whether severe or insignificant. The incidence has been given elsewhere as $0.7 \%$ for captopril and $1 \cdot 4 \%$ for enalapril, ${ }^{29} 6 \%$ for captopril ${ }^{1}$ and up to $10 \%$ for enalapril. ${ }^{7}$ Our findings indicate that the problem of cough may be greater with enalapril. Both the incidence and recovery time were appreciably greater for enalapril. The mean time of onset was shorter and the withdrawal rate higher for enalapril, but these differences were not significant.

The pathogenesis of the cough reaction is unknown. Most of the conversion from angiotensin I to angiotensin II occurs in the pulmonary vasculature. ${ }^{30}$ Thus a high local concentration of a product or products resulting from inhibition of angiotensin converting enzyme may act as an irritant in sensitive areas of the respiratory passages, producing the cough. Semple and Herd postulated that the cause may be potentiation of the effects of kinins on the airways resulting from inhibition of angiotensin converting enzyme. ${ }^{6}$ Captopril enhances bronchoconstriction induced by 
bradykinin in guinea pigs, ${ }^{31}$ and inhaled kinins can provoke bronchoconstriction in asthmatic patients. ${ }^{32}$ The data presented in this paper do not support a relation with asthma, but the mechanism of production of cough may be similar and might be mediated by the local irritant effect of increased bradykinin as suggested by Stark. ${ }^{33}$ Any postulated mechanism for the reaction would need to take into account the preponderance of women among the patients with cough. The similar age distribution of the men and women and the fact that most of the women were postmenopausal suggests that sex hormones do not have an influence. Captopril enhances the release of prostaglandin-like substance from guinea pig lungs $\mathrm{s}^{31}$ and can increase production of prostaglandin $E_{2}$ in patients with hypertension. ${ }^{34}$ Prostaglandin $\mathrm{E}_{2}$ and others have an irritant effect on the respiratory tract, and so prostaglandins should be considered as possible mediators. ${ }^{35}$

We thank the doctors who reported the adverse reactions and $\mathrm{Mr}$ George Spears for his help with the statistics.

\section{References}

1 Havelka J, Vetter $\mathrm{H}$, Studer A, et al. Acute and chronic effects of the angiotensin-converting enzyme inhibitor captopril in severe hypertension. Am $\mathcal{J}$ Cardiol 1982;49:1467-74.

2 Groel JT, Tadros SS, Dreslinski GR, Jenkins AC. Long-term antihypertensive therapy with captopril. Hyperiension 1983;5(suppl III):145-51.

3 Smith WM, Kulaga SF, Moncloa F, Pigeon R, Walker JF. Overall tolerance and safety of enalapril. Fournal of Hypertension 1984;2:113-7.

4 Sesoko S, Kaneko Y. Cough associated with the use of captopril. Arch Intern Med 1985;145: 1524.

5 Cleland JGF, Dargie HJ, Ball SG, et al. Effects of enalapril in heart failure: a double blind study of effects on exercise performance, renal function, hormones and metabolic state. Br Hearn $\mathcal{f}$ 1985;54:305-12.

6 Semple PF, Herd GW. Cough and wheeze caused by inhibitors of angiotensin-converting enzyme. NEngl F Med 1986;314:61.

7 Hallwright GP, Maling TBJ, Town GI. Enalapril and cough: case report. NZ Med f 1986;99:66-7.

8 Mitchell A, Gillies A, Garney S, Smith AJ. Cough and captopril. Arch Intern Med 1986;146:1017.

8 Mitchell A, Gillies A, Garney S, Smith AJ. Cough and captopril. Arch Intern Med 1986;146:1017. 1986;135:217-8.

10 DiBianco R. Adverse reactions with angiotensin converting enzyme (ACE) inhibitors. Medical Toxicology 1986;1:122-41.
11 Todd PA, Heel RC. Enalapril. A review of its pharmacodynamic and pharmacokinetic properties and therapeutic use in hypertension and congestive heart failure. Drugs 1986;31:198-248.

12 McQueen EG. Intensified adverse drug reaction reporting scheme. NZ Med f 1977;85:296.

13 Coulter DM, McQueen EG. Post-marketing surveillance. Achievements and problems in the intensified adverse drug reaction reporting scheme. New Zealand Family Physician 1982;9:13-7.

14 Coulter DM, Edwards IR, McQueen EG. Post-marketing surveillance in the general population, New Zealand. In: Inman WHW, ed. Monitoring for drug safety. Lancaster, England: MTP Press, 1986:119-34.

15 Salena BJ. Chronic cough and the use of captopril: unmasking asthma. Arch Intern Med 1986;146:202-3.

16 Crombie A, Manson P, McVey D, et al. Once daily enalapril in general practice patients with mild to moderate essential hypertension. NZ Med f 1986;99:503-4.

17 Heel RC, Brogden RN, Speight TM, Avery GS. Captopril: a preliminary review of its pharmacological properties and therapeutic efficacy. Drugs 1980;20:409-52.

18 Vidt DG, Bravo EL, Fouad FM. Medical intelligence drug therapy: captopril. $N$ Engl 7 Med 1982;306:214-9.

19 Dollery CT. Safety and efficacy of enalapril. Summing up the evidence. Journal of Hypertension 1983;1(suppl 1):155-7.

20 Hodsman GP, Robertson JIS. Captopril: five years on. Br Med $\mathcal{~}$ 1983;287:851-2.

21 Davies RO, Irvin JD, Kramsch DK, Walker JF, Moncloa F. Enalapril worldwide experience. Am f Med 1984:77:23-35.

22 Frohlich ED, Cooper RA, Lewis EJ. Review of the overall experience of captopril in hypertension. Arch Intern Med 1984;144:1441-4.

23 McFate Smith W, Davies RO, Gabriel MA, et al. Tolerance and safety of enalapril. Br f Clin Pharmacol 1984;18:249-53S.

24 Edwards CRW, Padfield PL. Angiotensin-converting enzyme inhibitors: past, present and bright future. Lancet 1985;i:30-4.

25 Moncloa F, Stromovsky JA, Walker JF, Davies RO. Enalapril in hypertension and congestive heart failure. Overall review of efficacy and safety. Drugs 1985;30(suppl 1):82-9.

26 Riley LJ, Vlasses PH, Ferguson RK. Clinical pharmacology and therapeutic applications of the new oral converting enzyme inhibitor, enalapril. Am Heart $\mathcal{f}$ 1985;109:1085-9.

27 Ball SG, Robertson JIS. A need for new converting enzyme inhibitors? Br Med f 1985;290:180-1.

28 Town GI, Hallwright GP, Maling T, O’Donnell TV. Angiotensin converting enzyme inhibitors and cough. NZ Med I 1987;100:161-3.

29 Stumpe KO, Kolloch R, Overlack A. Captopril and enalapril: evaluation of therapeutic efficacy and safety. Practical Cardiology 1984;10:111-24.

$30 \mathrm{Ng} \mathrm{KKF}$, Vane JR. Conversion of angiotensin I to angiotensin II. Nature 1967;216:762-6.

31 Greenberg R, Osman GH, O'Keefe EH, Antonaccia MJ. The effects of captopril (SQ 14,225) on bradykinin-induced bronchoconstriction in the anesthetized guinea pig. Eur $\mathcal{J}$ Pharmacol 1979;57:287-94.

32 Varonier HS, Panzoni R. The effect of inhalations of bradykinin on healthy and atopic (asthmatic) children. Int Arch Allergy Appl Immunol 1968;34:293-6.

33 Stark RD. Mechanism of cough with angiotensin-converting enzyme inhibition. Arch Intern Med 1986;146:1227.

34 Swartz SL, Williams GH. Angiotensin-converting enzyme inhibition and prostaglandins. Am $\mathcal{J}$ Cardiol 1982;49:1405-9.

35 Smith AP. Lungs. In: Ramwell PW, ed. The prostaglandins. New York: Plenum Press, 1973; vol 1:203-18.

(Accepted 27 March 1987)

\section{SHORT REPORTS}

\section{Hypogonadism induced by luteinising hormone releasing hormone agonist analogues: effects on bone density in premenopausal women}

Luteinising hormone releasing hormone agonists can be used to treat several gynaecological and non-gynaecological conditions in women. By inducing reversible suppression of gonadotrophin secretion and subsequent hypooestrogenism luteinising hormone releasing hormone agonists may be useful in conditions related to sex hormones-for example, precocious puberty, uterine leiomyoma, ${ }^{1}$ and endometriosis. ${ }^{2}$

Most patients who receive luteinising hormone releasing hormone agonist treatment experience symptoms of oestrogen deficiency. ${ }^{2}$ In postmenopausal women hypo-oestrogenism may be associated with increased loss of bone mass. We determined the possible effects on skeletal bone mass of hypo-oestrogenism resulting from the therapeutic use of the potent luteinising hormone releasing hormone agonist (6-O-tert-butyl-D-serine)des-10-glycinamide-gonadorelin ethylamide (buserelin) (Hoechst Pharmaceuticals).

\section{Patients, methods, and results}

Thirteen patients aged 22-37 each received $400 \mu$ g buserelin intranasally every eight hours for six months as treatment for proved endometriosis. Trabecular bone in the spine and cortical bone in the femur were measured before and after treatment. The approval of the medical ethical committee and the informed consent of the patients were obtained.

The density of trabecular bone in the lumbar vertebrae (mean density in L2-4) was measured by computed tomography (General Electric 8600 scanner), with the patient lying on a calibration phantom. ${ }^{3}$ The precision for this technique is about $3 \%$, and the absorbed radiation dose was about $3 \mathrm{mSv}$ in the abdominal region for each measurement. The bone mineral content was measured at the centre of the right femur, where the bone is predominantly cortical, with a dual photon densitometer (Novo BMC-Lab 22a) that contained a source of gadolinium-153 (44 and $100 \mathrm{kEV}){ }^{4}$ The precision for these meaurements was about $1.5 \%$ and the radiation dose $0.1 \mathrm{mSv}$ at the site of measurement.

There was no significant change in patients' weight, diet, smoking, and exercise patterns during treatment. The mean (SEM) serum oestradiol $-17 \beta$ concentrations after three months' and six months' treatment were 141 (21) $\mathrm{pmol} / \mathrm{l}$ and 118 (27) pmol/l, respectively. Amenorrhoea was achieved in all patients after an initial slight withdrawal bleeding episode in the first month. Four patients had further occasional scanty losses during treatment. All but two patients experienced hot flushes and some had reduced vaginal secretions.

Before treatment the mean densities of trabecular and cortical bone were $184 \cdot 8$ $(7 \cdot 1) \mathrm{mg} / \mathrm{cm}^{3}$ and $3 \cdot 4(0 \cdot 1) \mathrm{g} / \mathrm{cm}$, respectively. There was a small but marginally significant reduction in both trabecular bone density in the lumbar vertebrae $(4 \cdot 6$ $(2 \cdot 1) \% ; p=0.06)$ and in bone mineral content for cortical bone in the femur and mid-shaft (table). In one patient the second computed tomographic measurement was not performed for technical reasons.

\section{Comment}

Genant et al reported a trabecular bone loss of $9 \%$ in the first year after surgical oophorectomy in 31 premenopausal women and a smaller effect on peripheral cortical bone. ${ }^{5} \mathrm{We}$ are currently trying to establish whether the return of ovarian steroidogenic activity after treatment with luteinising hormone releasing hormone agonist has been stopped results in the complete regain of trabecular bone lost because of the hypo-oestrogenism during treatment. Despite reduced circulating oestradiol concentrations some patients in this study did not show appreciable losses, and they need to be investigated further to see if it is possible to predict those patients who respond in this manner. 